\title{
Articles
}

\section{Anglophone, Peewee, Two-four ... Are Canadianisms Acquired by ESL Learners in Canada?}

\section{Hai Xu and Janice McAlpine}

This article examines the extent to which ESL learners studying in Canada acquire Canadianisms. Two instruments were used to assess the effect of posited variables on this acquisition: a lexical survey administered to 103 ESL learners in Kingston, Ontario; and a questionnaire about resources, teaching methods, and attitudes administered to their instructors. Results indicate that ESL learners' knowledge of Canadianisms is limited. No correlation exists between the time learners have spent in Canada and their knowledge of Canadianisms. The more relevant a Canadianism is to their life, the more likely ESL learners in Canada are to acquire it. Level of English proficiency does correlate positively with the acquisition of Canadianisms, but the variables of learners' L1 background and classroom English training are not shown to be significant. Two additional findings of this study deserve further attention. First, ESL instructors' attitudes toward teaching Canadianisms vary widely. Second, lexical items specific to a particular variety of a language - for example, the Canadian English vocabulary sampled in this study_may make manifest the assumptions and knowledge tacitly shared in a cultural group.

Cet article porte sur la mesure dans laquelle les apprenants en ALS qui étudient au Canada apprennent les canadianismes. Deux instruments ont servi dans l'évaluation de l'effet de variables présumées sur cette acquisition: une enquête lexicale auprès de 103 apprenants en ALS à Kingston, en Ontario, et un questionnaire pour les enseignants sur les ressources, les méthodes d'enseignement et les attitudes. Les résultats indiquent que les apprenants en ALS connaissent peu les canadianismes. Aucune corrélation n'existe entre le temps que les apprenants ont passé au Canada et leur connaissance des canadianismes. Plus un canadianisme est pertinent à la vie des apprenants, plus il est probable qu'ils l'apprennent. Alors que le niveau de compétence en anglais est directement corrélé à l'acquisition des canadianismes, les variables liées à la langue première et à la formation en ALS des apprenants ne semblent pas être significatives. Deux autres résultats de cette étude méritent plus d'attention. D'abord, les attitudes des enseignants en ALS face à l'enseignement des canadianismes divergent beaucoup. Deuxièmement, les items lexicaux qui sont spécifiques à une variété 
particulière d'une langue - par exemple, le vocabulaire canadien anglais à l'étude ici-peuvent servir d'indicateurs des hypothèses et des connaissances tacitement partagées par un groupe culturel.

\section{Introduction}

Do second-language learners acquire culturally specific vocabulary, and if they do, how and to what extent? Most L2 vocabulary studies to date have focused on L2 learners' lexical competence and performance in the classroom setting (Wode, 1999; Read, 2004). By examining culturally specific vocabulary, which we suspect is more likely to be learned on the street than in the classroom, we hope to gain some insight into a topic as yet inadequately explored in the literature, vocabulary acquisition in a natural setting. Another reason for looking more closely at culturally specific vocabulary is to shed light on the special difficulties it poses for the learner. It has long been noted that each variety of a language contains special, culturally conditioned vocabulary (Samovar, Porter \& Stefani, 2003), and it is commonly thought that the character of a particular region or country is vividly represented by its distinctive vocabulary. If this is so, then culturally specific vocabulary carries a particularly heavy semantic burden. Yet whether L2 learners have special difficulty in acquiring these lexical items has not been tested, and neither has there been a close examination of the nature of the difficulty posed by culturally specific lexical items.

Given these considerations, we have formulated the following research question: In a setting of direct exposure to a natural language and culture, do L2 learners acquire the vocabulary peculiar to that language and culture? Specifically, we are interested in the following issues: (a) Do ESL learners studying in Canada acquire Canadianisms? Insofar as they do, what factors affect their attainment? (b) What implications, if any, does the present study have for the instruction of ESL learners in Canada?

For the purposes of the present study, Canadianisms refers to a lexical item borrowed from another language into English in Canada (e.g., kayak, anglophone), coined in Canada (e.g., skidoo, separate school), or used with a peculiar meaning in Canada. An example of this last type is the word peewee. Peewee is used in many varieties of English, but has a special meaning in Canada in the domain of hockey and other sports. By our estimate, which we have based on dictionary counts, there are approximately 2,000 Canadianisms in the contemporary Canadian English variety.

\section{Theoretical Framework for the Present Study}

What factors come into play in the acquisition of L2 vocabulary? Gu (2003) proposes a "person-task-context-strategy" (p. 1) model, positing four main factors and many related subfactors. Gu's person is the learner, and the 
learner's attainment of vocabulary will be affected by his or her age, sex, language aptitude, intelligence, prior knowledge, motivation, self-concept/image, personality, and cognitive and learning style. Gu's task is what is to be accomplished, which may vary. Some learners may desire only to slog through technical articles competently, whereas others may wish to converse like a native speaker. Gu's context refers to the broader learning environment, not the classroom or the study, but the sociocultural-political environment where learning takes place. Gu's strategy is the "series of actions a learner takes to facilitate the completion of a learning task" (p. 3).

In the present study, we postulate five factors affecting the acquisition of Canadianisms by ESL learners, each of which is related to one of the main aspects of $\mathrm{Gu}^{\prime}$ 's model. We believe that learners' attainment will hinge on the following: (a) the relevance of Canadianisms to ESL learners (Gu's task); (b) the length of time learners have spent in Canada (Gu's context); (c) learners' levels of general English proficiency (Gu's person); (d) learners' L1 background (also Gu's person); and (e) the resources available to learners for acquiring Canadianisms (a determinant of Gu's strategy). Accordingly, we propose the following hypotheses.

First, the more broadly relevant a Canadianism is to life in Canada, the more likely it is that a learner will acquire it. In other words, degrees of usefulness exist among Canadianisms, and we do not expect learners to acquire them in random order.

Second, the longer a learner stays in Canada, the more likely he or she is to be exposed to a larger number of Canadianisms and to acquire them.

Third, the factor of the learner's English proficiency level will affect the acquisition of Canadianisms, but only slightly. We posit a weak connection between English proficiency level and acquisition of Canadianisms because we surmise that other factors, which we are not attempting to measuresuch as personality type-may be more relevant to the task.

Fourth, learners' native language might be a variable that affects their acquisition of Canadianisms.

Last but not least, we expect to find that international English learners studying in Canada are not systematically exposed to Canadianisms.

\section{Methodology}

\section{Instruments}

We designed two surveys to determine whether the study variables affected acquisition. The first, a lexical survey, was administered to ESL students. The second survey was administered to ESL teachers; it explored teachers' attitudes toward teaching Canadianisms and their approaches to teaching them. 


\section{Participants in the Surveys}

One hundred, three ESL students studying English as a second language in an EAP program at a university in Kingston, Ontario, took part in the first survey. Almost all these participants were international students residing in Canada for less than one year for the express purpose of studying English. For ethical considerations, the participants did not include elementary-level ESL learners.

In order to determine whether classroom instruction had an effect on the results, a control group was invited to participate in the lexical survey. The control group consisted of 16 Chinese visiting scholars in Ontario who did not receive any kind of regular English instruction in the classroom, but who did have exposure to the Canadian sociocultural context.

Eight ESL instructors participated in the teachers' survey; they were instructors in the same program as the students surveyed.

\section{Design of the First Lexical Survey}

The survey we administered to ESL students comprised three parts. Part I was solely a personal profile. Subjects were asked to provide basic information about themselves, including their native language, the number of years they had studied English, and the length of time they had been in Canada.

Each respondent also identified his or her English proficiency level. The ESL students participating in our survey had taken a stringent placement test on entering their current ESL program, and they were subsequently directed to classes according to proficiency level. Thus students were asked to identify their class level on the survey. As for the Chinese visiting scholars, they had had to pass the English proficiency test (EPT) administered in China to Chinese scholars wishing to become eligible to apply for study abroad. The EPT consists of five parts: writing, listening, grammatical structure and vocabulary, cloze, and reading comprehension. It is a test that only advanced learners of English could pass.

Parts II and III of the student survey consisted of the Canadianisms that were tested. Part II investigated ESL learners' definitional knowledge of Canadianisms. With our focus on culture, we were interested in what Laufer and Paribakht (1998) refer to as referential knowledge of lexemes rather than in learners' control of form and syntactic behavior in production. In designing this section, we adapted the Vocabulary Knowledge Scale (VKS) devised by Wesche and Paribakht (1996). Originally designed to chart stages in vocabulary acquisition, the multiple-choice format of the VKS also allows test-takers to select an answer even when they are unfamiliar with the lexical item. In this way, test-takers can avoid embarrassment when faced with a preponderance of unfamiliar lexical items. A sample item from the part of the test is provided below. 


\section{(1) anglophone}

$\square$ (a) I don't remember having seen this word before.

$\square$ (b) I have seen this word before, but I don't know what it means.

$\square$ (c) I have seen this word before, and I think it means: [Please give a definition]

(d) I know this word. It means: [Please give a definition]

Part III examined ESL students' receptive knowledge of Canadianisms. In designing this part, we used a more typical multiple-choice format, requiring subjects to choose the best equivalent. The following is a sample.

(17) What message is the justice system conveying to potential impaired drivers?

$\square$ (a) drivers who steal other people's cars;

$\square$ (b) drivers who are under the influence of alcohol or drugs;

$\square$ (c) drivers who are physically disabled;

$\square$ (d) drivers who are sleepy while driving.

Parts II and III each tested 15 Canadianisms. The following considerations influenced the selection of test items. Each test lexeme was used (or the meaning being presented was used) only in Canada. The test lexemes were drawn from broadly experienced sectors of Canadian life such as food and drink (e.g., chip wagon, two-four), money (e.g., loonie, toonie) and hockey (e.g., peewee, atom). The set of test words included some that we thought ESL learners would easily recognize (e.g., UHIP, GST) and some that we expected to be puzzlers (e.g., have province, atom hockey). All the test lexemes (listed and glossed in Appendix A), with the exception of UHIP, we expected to be familiar to permanent residents of Ontario. Several of the survey items were in fact "Ontarianisms": in other words, Canadianisms specific to one large and highly populous region of the country, the province of Ontario. If we had administered this survey in another province or territory, we would have substituted regionally equivalent vocabulary for these items.

The following scoring method was adopted: In Part II, the VSK shell was ignored and only the definitions jotted in at (c) or (d) were examined. If the participant offered a correct (or even approximately correct) explanation of the Canadianism, one mark was awarded. Part III was more straightforward: one mark was awarded for the correct multiple-choice response. Thus the highest score possible for each part was 15, and the lowest 0; full marks for the whole survey: 30 .

\section{Design of the Second Lexical Survey}

The second survey aimed to investigate the ESL instructors' attitudes toward teaching Canadianisms and to elicit their methods of teaching them. In this partly open-ended survey, we asked the teachers what Canadianisms they had taught, what their attitude to teaching Canadianisms was, what meth- 
ods of instruction they used, and what resources for learning Canadianisms they could suggest to ESL learners.

\section{Results}

\section{Data Screening}

Before analyzing the data, we screened the data provided by the 103 participants of the first lexical survey and identified and removed five statistical outliers on the variable of learners' L1 background: one participant did not indicate his/her native language, and the language groups for German, Hungarian, Portuguese, and Russian were too small, with only one participant in each group.

In addition, the variable of the length of stay in Canada was severely skewed by the two cases of Francophone Canadians who had each lived in Canada for about 21 years. Thus we analyzed the results from just 96 surveys in our final data analysis.

\section{General Results of the First Lexical Survey}

Among our test group of 96 ESL learners, the highest scorer correctly identified 21 of 30 test items (70\%). The lowest score was $1(3.33 \%)$. The participants achieved a mean score of $10.52(35.07 \%)$, with a standard deviation of 3.92. Thus we can see that these ESL learners showed a limited knowledge of Canadianisms.

The 96 participants performed better in Part III than in Part II. This means that as one would expect, their receptive knowledge of Canadianisms was better than their explicit knowledge (see Table 1). A paired-samples $t$-test determines whether differences in mean scores can be accounted for by random fluctuations in test sets, and in this case, the test indicated that there was a statistically significant gap between the learners' explicit or definitional and their receptive knowledge of Canadianisms $(t=-10.51, d f=95$, $p<.01)$.

\section{Relevance of Canadianisms to ESL Learners}

Focusing on individual items tested in the survey, results show that these ESL learners had not picked up Canadianisms randomly. Some Canadi-

Table 1

ESL Learners' Scores in the Lexical Survey.

\begin{tabular}{lrrr}
\hline & $M$ & $S D$ & Range \\
\hline Whole test (30 items) & 10.52 & 3.92 & $1-21$ \\
Part II (15 items) & 3.68 & 2.07 & $0-8$ \\
Part III (15 items) & 6.99 & 2.84 & $0-13$ \\
\hline
\end{tabular}


anisms (e.g., UHIP, the First Nations people, LCBO, loonie, francophone) were well recognized. Over $70 \%$ of the ESL learners knew the meanings of UHIP, loonie, and francophone. Other Canadianisms were quite unfamiliar. Fewer than $10 \%$ of the participants knew the meanings of band council, chip wagon, premier, Canuck, or peewee. Thus two distinct categories of Canadianisms (familiar vs. unfamiliar) emerged.

\section{Correlation Between Length of Stay in Canada}

and Knowledge of Canadianisms

The learning context is a factor that we quantified as length of time spent in Canada. Results indicate that the 96 subjects had stayed in Canada for an average of 7.44 months, with the range from 1 month to 37 months.

Does the variable of length of stay in Canada correlate with the test results? A Pearson Correlation Test produced a statistically insignificant result $(r=.172, p>.05)$. In other words, these ESL learners' knowledge of Canadianisms appeared to have nothing to do with the duration of their stay in Canada.

\section{Effect of English Proficiency Level and L1 Background on}

\section{Knowledge of Canadianisms}

The data were further analyzed using a two-way ANOVA. The ESL learners' scores for the lexical survey were designated as the dependent measure for this two-way ANOVA, and the learners' English proficiency level and their native language were the independent variables.

According to the English proficiency levels that they reported, the 96 student participants fell into three groups: intermediate learners (54 participants), advanced learners (31), and continuing-advanced learners (11). Most continuing-advanced learners had already successfully completed the advanced curriculum in their ESL program. In compliance with guidelines suggested by a research ethics review committee, elementary-level ESL learners were excluded from the lexical survey. The subject pool comprised five first-language groups: Korean (29 subjects), Japanese (27), Chinese (26), Arabic (8), and Spanish (6).

The two-way ANOVA results indicated that these ESL learners' knowledge of Canadianisms was significantly affected by their proficiency level $(F=7.821, d f=2, p<.05)$, but not by their native language $(F=.367, d f=4, p>.05)$. The interaction of these ESL learners' proficiency level and their L1 was insignificant $(F=.472, d f=7, p>.05)$. In other words, an advanced or a continuing-advanced ESL learner regardless of his or her L1 background is likely to pick up more Canadianisms than an intermediate learner (see Figure 1). 


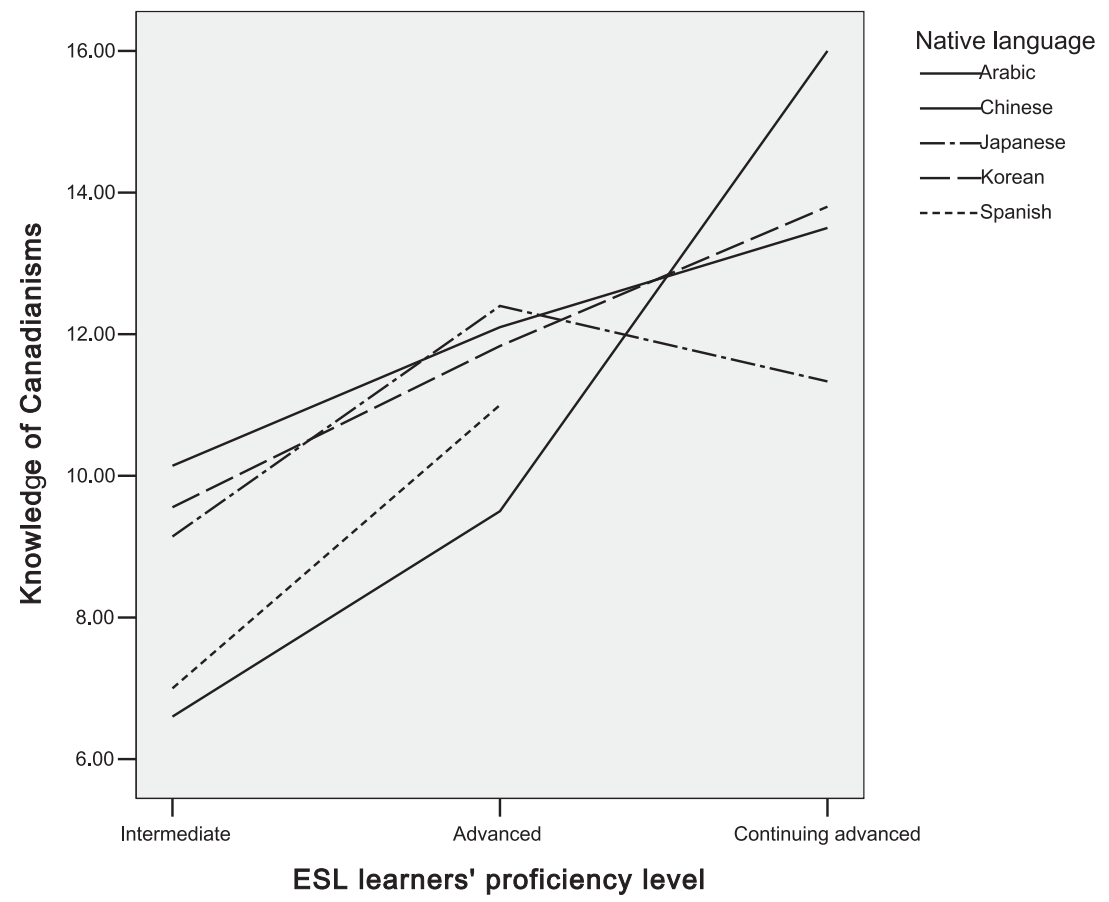

Figure 1. Effects of ESL learners' proficiency level and their L1 background on their knowledge of Canadianisms.

Effect of Classroom Instructions on the Acquisition of Canadianisms

We wondered if classroom instruction played a role in the acquisition of Canadianisms: was there any difference between the scores of the ESL students who had regular English training in classroom and the scores of the Chinese visiting scholars who were exposed to the university milieu but did not receive any regular English training?

As the Chinese visiting scholars were believed to have reached an advanced or above proficiency level, we felt it would be reasonable to make a comparison between the 16 scholars and the 42 ESL students at the advanced and continuing-advanced levels.

The one-way ANOVA result $(F(1,56)=1.289, p>.05)$ indicated no statistically significant difference between the scores of the two groups. So according to our data, classroom instruction per se was not a variable affecting the acquisition of Canadianisms by these learners. Of course, classroom instruction was significant indirectly insofar as it had contributed to each participant's general level of proficiency. 


\section{Relationship Between the Teaching and the Acquisition}

of Specific Canadianisms

The question of the effectiveness of classroom instruction can be looked at from another angle. Are Canadianisms that teachers report that they have taught in class more familiar to the ESL students than those no teacher claims to have taught? Results tabulated from the survey of teachers indicate that seven of the eight teachers (accounting for $87.5 \%$ ) claimed to have taught the Canadianism loonie in class; five $(62.5 \%)$ had taught GST, the First Nations, and RCMP; four (50\%) had taught anglophone, premier, toonie, PST, and francophone; three (37.5\%) had taught $L C B O$, two-four, Canuck, and have province; two (25\%) had taught impaired driving, bachelor, and whiteout; and one (12.5\%) had taught UHIP, Canadian Tire money, have-not province, crown corporation, baby bonus, and OHIP. Canadianisms appearing in the students' lexical survey that no teacher claimed to have taught include chip wagon, peewee, atom hockey, homebrew, break-up, joe job, and band council.

A Pearson Correlation test was conducted to examine whether there was a correlation between the teaching of, and the acquisition of, a given Canadianism. In order to do this, we weighted the Canadianisms as follows. Canadianisms that seven teachers claimed to have taught were assigned a weight of 7 (e.g., loonie, 7); those five teachers claimed to have taught a weight of 5 (e.g., GST, RCMP), and so forth. Test item by test item, the average scores attained by the student group were compared with the how-often-taught weights that we assigned. The result of the comparison $(r=.19, p>.05)$ indicates no direct correlation between the teaching of and acquisition of these Canadianisms. That is, a teacher's teaching of a Canadianism seemed to have no direct bearing on its retention by a student.

This finding should be interpreted cautiously. All instructors and students participating in our surveys did so voluntarily and anonymously. So first, we have no way of knowing whether the teachers who reported on their teaching practices were the current instructors of the students who participated in the student survey. Teachers and students certainly were drawn from the same program, but it is possible that there was no direct match between participating instructors and classes. Our teachers' survey data provided us with only a measure of the likelihood of a particular Canadianism's having being taught. Second, teachers did not know of our survey in advance and were not attempting to teach Canadian vocabulary systematically.

\section{The Teaching of Canadianisms: Why and How}

Finally, we explored whether these international ESL students were taught or systematically exposed to Canadianisms while in Canada. We began looking at this question above when interpreting the results of the lexical 
survey, but here we also summarize the responses of the teachers to their survey (reproduced in Appendix B).

The surveyed teachers had sharply divided views on teaching Canadianisms in class. Among the eight teachers, four said that they would make a point of teaching Canadianisms, and four said they would not.

When asked whether they would deal with Canadianisms as they came up in class, five said yes, one no, and two did not answer. Five teachers said they frequently taught Canadianisms in class, one very frequently, one occasionally, and one did not indicate.

These responses show that although more than half of these teachers had an interest in teaching Canadianisms in class, some did not like the idea. One teacher elaborated:

I believe multicultural materials are great and although the students are now in Canada, I don't want to force Canadiana on anyone. As well, I believe that we are supposed to be a multicultural country, and therefore a great thing about living here is that one can learn about many cultures. Basically I encourage students to read materials which are well written and valuable regardless of where they were printed. Obviously one cannot assume that all ESL teachers in Canada wish to teach Canadianisms.

Six teachers said that they always suggested to students that they read newspapers, magazines, or books published in Canada, or listen to radio or watch TV programs specifically related to Canada; one teacher said frequent$l y$; and one said sometimes. Most teachers believed that the Canadian media were a useful resource for information about Canadian culture.

When asked what methods they would use in teaching Canadianisms, all the teachers surveyed said that they would explain the meanings of Canadianisms in reading or listening materials or at students' request; two said they would also ask students to look up a word in a Canadian English dictionary; and no teacher chose the last alternative: to ignore Canadianisms that did not impede students' understanding of a text.

Some teachers suggested other possible strategies for teaching Canadianisms: (a) using local materials (e.g., newspapers); (b) giving students a list of Canadian words and acronyms and asking them to consult native speakers; (c) focusing a lesson on Canadian English; (d) asking students what they thought some Candianisms meant and discussing equivalents in their cultures; and (e) introducing pertinent Canadianisms before assigning a reading. Clearly teachers were aware of resourceful methods for teaching Canadianisms. And methods (b) and (d) involve actively seeking and evaluating information about new words that is considered to contribute to retention (Read, 2004).

However, apart from the Canadian media, these teachers knew of few resources to support the teaching of Canadian English. One teacher men- 
tioned the CBC television special Talking Canadian (2004); one gave the title Canadian Sayings: 12 Folk Sayings Used by Canadians (Casselman, 1999); one knew the Guide to Canadian English Usage (Fee \& McAlpine, 2007); one mentioned the Canadian Oxford Dictionary (Barber, 2004) and Canadian English ESL/EFL Web sites (TESL Ontario Web links, e.g., http:/ /www.teslontario. org./new/links/links_instr.htm).

Two teachers mistakenly thought that Longman had produced a Canadian English dictionary, and two teachers did not respond to the question that asked what Canadian English dictionaries or resources they knew of.

Summaries of the Results

To summarize, these ESL students' knowledge of Canadianisms was limited. They were familiar with some Canadianisms (e.g., UHIP, the First Nations people, LCBO) and unfamiliar with others (e.g., band council, have-not province, chip wagon). No correlation was found between the time they had spent in Canada and their knowledge of Canadianisms. Their English proficiency level was clearly linked to their acquisition of Canadianisms, but classroom English training per se did not appear to play a significant role.

More than half the teachers showed a positive attitude toward teaching Canadianisms and could suggest teaching methods. However, these ESL teachers generally were not much aware of English-language reference resources produced specifically for Canadians.

\section{Discussion}

\section{Why Learners Learn and What They Learn}

Why do learners learn some Canadianisms and not others? Students' motivation apparently plays a role here. ESL students for the most part are not coming to Canada to learn Canadianisms. We suspect that highly motivated students acquire particular Canadianisms incidentally.

ESL students' spotty knowledge of Canadianisms can also be partly explained by the communicative strategies these learners develop (Corder, 1983). Learners are continually faced with gaps in their L2 vocabulary, and they use strategies such as approximation (e.g., a hat instead of a tuque), circumlocution (e.g., one- or two-dollar coin instead of loonie, toonie). Only those Canadianisms that are useful in daily life and that cannot be replaced by a known equivalent in British or American English are likely to interest learners: these terms they will be compelled to learn. For example, every international student has to buy health insurance while at a university in Ontario, so international students naturally acquire the term UHIP (compare their unfamiliarity with $O H I P)$. Another case in point is $L C B O$. Students who frequent the liquor store certainly know the significance of this acronym. 
Our findings also seem to reflect interlanguage development. Some students knew quite well that loonie and toonie referred to coins; however, they were confused about which term referred to a one-dollar coin and which to a two-dollar. Two-four provides another example of evolving vocabulary knowledge. One student defined the phrase thus: "I think it is about one of the way of the measure of alcohol." We expected to find that a longer exposure to Canadian English would cause fuzzy interlanguage definitions to become increasingly refined and accurate. Thus we were surprised to find no correlation between the length of time these learners had spent in Canada and their knowledge of Canadianisms.

This lack of correlation may be in part explained by the findings of Laufer and Paribakht (1988) who, in a study of vocabulary activation, noted that "the benefits of residence in an L2 context only began to appear after about 2 years" (p. 366). Because the ESL students we tested had lived in Canada on average only 7.44 months, the duration-of-stay variable in our shorter time frame may not have shown its potential significance.

Our hypothesis of a weak correlation between English proficiency and mastery of Canadianisms was also disproved. In other words, we underestimated the effect of English proficiency level on the acquisition of Canadianisms. We assumed that proficiency scores would reflect textbook learning and that more telling factors in the acquisition of Canadiansims would be learners' personality types and their willingness to engage in conversation with Canadians. Probably we underestimated the capacity of the university's ESL placement test to assess not merely our participants' mastery of the rules of English grammar, but also their communicative competence. In other words, the more highly placed students at the institution where we conducted our survey were probably exactly those most likely to exploit the natural setting and engage Canadians in conversation. The more proficient speakers of English had more resources for learning new words (including Canadianisms).

Finally, why overall did these ESL learners demonstrate such a limited knowledge of Canadianisms? A glance at the list of Canadianisms tested (see Appendix A) shows that 12 of the 30 items are multiword units, which in fact could be increased to 20 of 30 if solid compounds (e.g., homebrew) and acronyms were regarded as multiword units, which at deeper levels of understanding they certainly are. In this respect it may be noteworthy that although Huckin and Coady (1999) report that non-native-speaking teachers of English in France had a knowledge of low-frequency English words equivalent to that of university-level native speakers, they also observed that those teachers did not approach native speakers in their knowledge of multiword lexical items. Thus two related factors may be at play. First, a disproportionate quantity of culture-specific and culturally freighted vocabulary consists of multiword units (Cowie, 2001). Second, multiword 
units are more difficult for learners to recognize, to look up, and to use appropriately (compare Granger, 2001).

\section{Why Teachers Are Divided About Teaching Canadianisms}

Why are some ESL teachers reluctant to teach Canadianisms? From this point on, our reflections require us, the co-authors of this paper- $\mathrm{Xu}$ (from China) and McAlpine (from Canada) - to acknowledge the duality of our perspective. $\mathrm{Xu}$ initially assumed that Canadians would want to promote their culture and expand the use of their own particular variety of English. It appeared to $\mathrm{Xu}$ that one major stumbling block was a lack of recognition of the existence of Canadian English, even among native Canadians. However, the ESL teachers we surveyed demonstrated ingenuity in meeting the challenge of teaching culturally specific vocabulary. Thus to Xu's mind, what was lacking was the governmental or institutional will to expand the sphere of influence of Canadian English, an initiative that could be translated into policy directives for teacher training, curriculum design, and classroom resource selection.

When international students studying French attend the Sorbonne in Paris, they expect to learn Parisian French and to drink at the fountain of French culture. So why, Canadian co-author McAlpine wondered, is it not a matter of course for the Canadian government, for Canadian universities, and for Canadian ESL teachers systematically to instruct international students in Canadian culture and the particularities of Canadian English?

One reason for Canada's lack of linguistic self-promotion may be its colonial heritage. Although Canadian English had been differentiating itself from British-and to a lesser extent from United States-English for centuries, it was not until the Centennial of Canadian Confederation in 1967 that Canadian English coinages, spellings, meanings, and pronunciations were codified in a general dictionary of English for Canadians (the Canadian Senior Dictionary, 1967, in the Dictionary of Canadian English series edited by Avis, Drysdale, Gregg, \& Scargill). To this day many patriotic Canadians assume that proper Canadian English spelling is simply British English spelling, although in fact these same Canadians would be highly unlikely to write gaol, kerb, aluminium, or oestrogen. In addition, because most linguistic features of Canadian English, apart from the lexemes that form the basis of this study, are shared with either British or US English, Canadian English is rarely recognized even by its own speakers as a variant unto itself. Following the References, we list additional scholarly and popular resources describing the Canadian national variety of English.

A second practical reason why some teachers teaching English to international students in Canada do not highlight distinctively Canadian linguistic features is that these teachers know that their students will return to countries where they will be required to write English examinations either in 
British or US English. Studying English in Canada is probably a boon to international students in one way, for they are exposed to a hardy hybrid variety of English, an English that quite possibly suggests the future shape of World English: a dialect that is tolerant of variation including alternative spellings, pronunciations, and lexemes. However, the systematic (as opposed to incidental or accidental) teaching of Canadianisms and Canadian English linguistic features could well be regarded by some international learners as a muddying of the pure streams of British or US English. It seems obvious that teaching peculiarly Canadian vocabulary is appropriate in a LINC program for newcomers to Canada, but less obvious that such a focus would serve the needs of international students in a university EAP program.

A third, pedagogical reason why Canadian ESL teachers may hesitate to promote not only Canadian English, but also Canadian culture generally is suggested by the teacher whose survey response is quoted above. This teacher did not want "to force Canadiana on anyone" and believed "that we are supposed to be a multicultural country, and therefore a great thing about living here is that one can learn about many cultures." Teachers are at a linguistic advantage in the second-language classroom in that they are using their first (or a very well mastered second) language, while their students are typically struggling to express themselves. A curriculum that emphasizes Canadian content further privileges the ESL teacher in relation to the students because with such a syllabus, the teacher is not only the only one in the classroom who can express herself or himself flawlessly, but also the only one with any expertise at all in the subject matter: Canadian culture. In order to redress the communicative power imbalance between teacher and student in the ESL classroom and also in order to find a way to engage students in meaningful speech tasks, some ESL teachers prefer a curriculum that draws more heavily on the experiences and expertise of the students.

Finally, many Canadians eschew flag-waving. Canada is an outwardlooking nation, its populace woven from and into the world community. Some Canadian ESL teachers regard themselves as post-nationalists and are unwilling to focus on the small linguistic and cultural differences that separate people. Pennycook (2007) critiques the investigation of national varieties of English as a spurious nod to pluralism in a social construction of reality that validates the global economic status quo by enshrining standard native-speaker English at the center of the linguistic world map. Yet we would argue that remaining in ignorance of the specificity of one's nativeor the ambient-dialect of English reinforces a monolithic view of English and militates not only against any meaningful appreciation of cultural and linguistic pluralism, but also against the effective use of English as a lingua franca. To offer a mundane but not trivial example, Canadian ESL teachers do international students a disservice when they send them into the wider 
English-speaking world trained to ask politely for the washroom. No one outside Canada uses this word to refer to that essential facility.

What a List of Its Peculiar Vocabulary Can Reveal About a Culture

We end this article by discussing an unexpected result of our collaboration. As we discussed which Canadianisms might be suitable for inclusion in the lexical survey, one author, $\mathrm{Xu}$, deepened his understanding of Canadian culture, and the other, McAlpine, began to see her culture with fresh eyes. It had never occurred to McAlpine, for example, how opaque and anachronistic the term Mounties was: the everyday term Canadians use for the members of their national police force. Of course, Mounties were once mounted: they ranged over the northwestern perimeter of the country on horseback. For his part $\mathrm{Xu}$ was surprised at the Canadianism baby bonus. Coming from a country that has for years been enforcing a one-child policy in an attempt to combat overpopulation, $\mathrm{Xu}$ had difficulty imagining a responsible government encouraging natalism. The Canadianism homebrew, McAlpine realized, reflects both Canadians' love of beer and their fear of being dominated by Americans in the field of sports. And national protectionism in Canada is not confined to the football field. The desire for cultural sovereignty (another Canadianism) informs broadcasting and media policies as well. We observed that in general, culturally specific terms require more explaining and more contextualizing than interdialectally shared vocabulary; as such, they may constitute rich teaching material.

We began to realize that the seemingly superficial task of extracting Canadianisms from dictionaries had led us into detailed discussions of Canadian demographics, history, climate, institutions, pastimes, and values. We realized that many Canadianisms did not have equivalents in Chinese or even in the lexicons of other varieties of English, for they were deeply rooted in Canadian realities. This led us to the idea that the full set of lexical items peculiar to any region or culture might provide a starting point for exploring a notoriously elusive aspect of culture: the knowledge assumed and the values tacitly shared within a cultural group. This is an idea that we believe deserves further study.

\section{Acknowledgments}

This research was supported by the MOE Project of the Centre for Linguistics and Applied Linguistics at Guangdong University of Foreign Studies, by Canada-China Scholars' Exchange Programme (CCSEP), and by the Strathy Language Unit, Queen's University. We are grateful to Dr. Andy Curtis, Ms. Toni Thornton, and the teachers and students at the School of English, Queen's University for their support of, administration of, and participation in the lexical and teachers' surveys.

\section{The Authors}

Hai $\mathrm{Xu}$ is an associate professor of English in the Centre for Linguistics and Applied Linguistics at Guangdong University of Foreign Studies (GDUFS). He has a doctorate in linguistics from 
GDUFS. In the academic year 2003-2004, he was a CCSEP visiting scholar at the Strathy Language Unit in the Department of English at Queen's University in Canada. His research interests include lexicography and second-language vocabulary acquisition.

Janice McAlpine is the Director of the Strathy Language Unit in the Department of English at Queen's University in Canada. She has an MA (English) from the University of Toronto. She is co-editor of the Oxford Guide to Canadian English Usage $(1997,2007)$. Her research interests include English in Canada and corpus lexicography.

\section{References}

Avis, W.S., Drysdale, P.D, Gregg, R.J., \& Scargill, M.H. (Eds.). (1967). Canadian senior dictionary. Toronto, ON: Gage.

Casselman, B. (1999). Canadian sayings: 1200 folk sayings used by Canadians. Toronto, ON: McArthur.

Corder, S.P. (1983). Strategies of communication. In C. Færch \& G. Kasper (Eds.), Strategies in interlanguage communication (pp. 15-19). New York: Longman.

Cowie, A.P. (Ed.). (2001). Phraseology: Theory, analysis, and applications. Oxford, UK: Oxford University Press.

Granger, S. (2001). Prefabricated patterns in advanced EFL writing: collocations and formulae. In A.P. Cowie (Ed.), Phraseology: Theory, analysis, and applications (pp. 145-160). Oxford, UK: Oxford University Press.

Gu, P.Y. (2003). Vocabulary learning in a second language: Person, task, context and strategies. TESL-EJ, 7(2), 1-25.

Huckin, T., \& Coady, J. (1999). Incidental vocabulary acquisition in a second language: A review. Studies in Second Language Acquisition, 21(2), 181-193.

Laufer, B., \& Paribakht, T.S. (1998). The relationship between passive and active vocabularies: Effects of language learning context. Language Learning, 48, 365-391.

Mosgoret, A.M., \& Gardener, R.C. (2003). Attitudes, motivation, and second language learning: A meta-analysis of studies conducted by Gardener and associates. Language Learning, 53, 167-210.

Pennycook, A. (2007). The myth of English as an international language. In S. Makoni \& A. Pennycook (Eds.), Disinventing and reconstituting languages (pp. 90-115). Clevedon, UK: Multilingual Matters.

Read, J. (2004). Research in teaching vocabulary. Annual Review of Applied Linguistics, 24, 146-161.

Samovar, L., Porter, R.E., \& Stefani, L.A. (2003). Communication between cultures (5th ed.). Belmont, CA: Wadsworth.

Wesche, M., \& Paribakht, T.S. (1996). Assessing second language vocabulary knowledge: Depth versus breadth. Canadian Modern Language Review, 53, 13-40.

Wode, H. (1999). Incidental vocabulary acquisition in the foreign language classroom. Studies in Second Language Acquisition, 21, 243-258.

\section{Additional Resources on Canadian English}

Anthropology Department, University of Arizona. (2001). Canadian English. Retrieved July 10, 2008, from: http://www.ic.arizona.edu/ lsp/

Barber, K. (Ed.). (1998/2004). The Canadian Oxford dictionary. Toronto, ON: Oxford University Press.

Barber, K. (2007). Only in Canada, you say: A treasury of Canadian language. Toronto, ON: Oxford University Press.

Fee, M., \& McAlpine, J. (2007). Guide to Canadian English usage (2nd ed.). Toronto, ON: Oxford University Press.

Meyer, M.L.G. (Ed.). (2008). Anglistik 19(2) (special issue devoted to Canadian English). 
Pratt, T.K. (1993). The hobgoblin of Canadian English spelling. In S. Clarke (Ed.), Focus on Canada: Vol. 11 Varieties of English around the world (pp. 45-64). Amsterdam: John Benjamins. Slaght, M. (Director \& Producer). (March 1, 2004). Talking Canadian [Television series episode]. In S. Pin (Producer) The Canadian Experience. Toronto: CBC.

\section{Appendix A \\ 1 anglophone \\ 2 GST \\ 3 premier \\ 4 toonie \\ 5 LCBO \\ 6 UHIP \\ $7 \quad$ First Nations \\ 8 Canadian Tire money \\ 9 tuque \\ 10 chip wagon \\ 11 two-four \\ 12 RCMP}

Definitions of the Canadianisms Used in the Lexical Survey

13 peewee

14 have-not province

15 Canuck

16 loonie

17 impaired

18 PST

19 bachelor

20 atom hockey

21 have-province

22 francophone a speaker of English, esp. a native speaker

Goods and Services Tax, a federal tax of $7 \%$ (at the time of the survey, now $5 \%$ ) on goods and services purchased

the political leader of a province or territory, analogous to the prime minister of the country

informal, a two-dollar coin. Toonie is a blend of two and loonie.

Liquor Control Board of Ontario: The LCBO most commonly refers to the closest outlet in the chain of liquor stores owned and operated by the province.

University Health Insurance Plan, a group health care plan in which international students studying at Ontario universities are typically required to enroll.

the Aboriginal peoples of Canada formerly called Indians (thus not the Métis or Inuit)

discount coupons resembling play money issued by Canadian Tire, a

Canada-wide retail chain offering automotive supplies and service, hardware, housewares, etc.

a knitted cap, usually worn in cold weather.

a van parked at the side of the road selling fast food items such as French fries (chips), hamburgers and hot dogs.

a case of 24 beers.

Royal Canadian Mounted Police, Canada's national police force. Note: RCMP officers, who wear distinctive dress uniforms consisting of scarlet serge tunics, wide-brimmed hats, and riding boots, are known informally as Mounties. However, few Mounties today are mounted, i.e., work on horseback.

an age group in children's sports leagues, especially hockey. "A peewee" is a player within that age group (usually 12-13).

a poorer Canadian province, specifically a province on the receiving end of federal tax-sharing schemes designed to provide comparable government services and social benefits to Canadians in every province and territory.

a nickname for a Canadian; also in the plural the name of the major league Vancouver hockey team.

informal, a Canadian one-dollar coin, or the name of the Canadian dollar in international currency markets.

adjective: affected to the point of incompetence by alcohol or drugs; noun: the criminal or traffic offence of driving while impaired.

Provincial Sales Tax, a tax of $8 \%$ on retail sales in Ontario.

a small apartment in which a single room serves as both living room and bedroom.

an age group in children's hockey, usually 9-11 (see 13 above).

one of the richer Canadian province (see 14 above).

a speaker of French, especially a native speaker. 
23 whiteout

24 homebrew a snowstorm reducing visibility to zero.

informal, a Canadian athlete on a Canadian professional sports team, especially a Canadian-born Canadian Football League player. (The CFL limits the number of American players allowed on each team.) Also, any local athlete on a team that recruits players from a wide region.

25 crown corporation a national or provincial service owned by the government but operated as a separate business, for example, Canada Post, the CBC (Canadian Broadcasting Corporation), Air Canada, Hydro-Québec, BC Ferries.

26 break-up (springtime) the breaking into pieces of the solid ice covering lakes, rivers, etc.

27 joe job

28 baby bonus

a job that is poorly paid and menial, or a task that is unrewarding. formerly a government cheque mailed monthly to all parents to help defray the costs of raising children. The federal child subsidy now takes the form of a non-universal tax benefit and a universal child-care benefit for children under age 6 . These and similar provincial benefits are sometimes still called the baby bonus.

29 band council an elected chief and councillors governing the Aboriginal people, or band, associated with a particular reserve, or government-designated Indian territory.

30 OHIP

healthcare insurance plan for permanent residents of Ontario.

\section{Appendix B}

A Survey of Canadian English Vocabulary Instruction

Purpose of the Survey

To investigate teachers' views on teaching Canadianisms.

What is a Canadianism?

By a Canadianism, we mean a word or usage peculiar to Canadian English, such as loonie, RCMP, etc

\section{Survey Questions}

1. Which of the following Canadianisms have you explicitly taught in your EFL classes? Please check with " $\sqrt{ }$ ".

aloonie / $\square$ toonie

口UHIP / 口OHIP

$\square$ anglophone/ $\square$ francophone

口GST / 口PST

$\square \mathrm{LCBO}$

$\square$ have province /

$\square$ have-not province

$\square$ Canuck

$\square$ (spring) break-up

$\square$ peewee / $\square$ atom [hockey]

$\square$ premier [head of a province]

口bachelor [for rent]

$\square$ RCMP

$\square$ Canadian Tire money

$\square$ the First Nations people

口chip-wagon

atwo-four [beer]

$\square$ whiteout [snowstorm]

口crown corporation

$\square$ homebrew [sports player]

$\square$ tuque

口impaired (driver)

$\square$ the baby bonus

$\square$ joe job

aband council

2. Can you think of Canadianisms you have taught that are not listed above? Please list them.

3. Do you make a point of teaching Canadianisms?

口No $\square$ Yes

Or do you deal with them if they come up in your class?

口 No $\square$ Yes 
If yes, please indicate the frequency of their instruction:

$\square$ Very frequently $\square$ Frequently $\square$ Occasionally

4. Could you please specify your methods in of teaching Canadianisms? (You can choose more than one answer)

$\square$ Explain the meanings of Canadianisms whenever they appear in reading or listening materials.

$\square$ Ask students to look these words up in a Canadian English dictionary.

$\square$ Explain a Canadianism at the request of a student.

口Ignore Canadianisms if they do not impede students' understanding of a text.

口Other strategies. Please indicate:

5. Have you ever suggested to your students that they should read newspapers, magazines or books published in Canada, or listen to radio or watch TV programs specifically related to Canada?

$\square$ Always encourage them to do so.

$\square$ Frequently ask them to do so.

$\square$ Sometimes ask them to do so.

$\square$ Never ask them to do so.

Please indicate what reasons motivate your choice above.

6. If there were vocabulary lists or other teaching materials available to you that covered common Canadianisms, would you be likely to make use of them in your classes? Why or why not?

7. Do you know any dictionaries or books that contain explanations of Canadianisms? Please give their titles.

THANK YOU VERY MUCH FOR YOUR COOPERATION!

Appendix re. Ethical Considerations (added later by invitation)

Authors' Comments on the Research Ethics Process

Before we conducted the lexical surveys for students and teachers in the School of English (SoE) at Queen's University, our research was reviewed and certified as acceptable by Queen's University General Research Ethics Board (GREB). In our initial submission to the GREB, we described our methodology/procedures as follows:

1. Contact Director of School of English for permission to e-mail all SoE instructors;

2. Send instructors a letter describing the research project;

3. Follow-up with an e-mail to individual instructors asking if they are willing to describe the project to their classes;

4. No survey to occur in the class of any instructor who do not answer affirmatively;

5. If most instructors agree to participate, consult the Director of School of English and decide on a particular day on which the surveys can be administered in all classes;

6. On that day have instructors explain the purposes of the lexical survey to their classes, emphasize that the survey is not a test, and invite students to take part;

7. If most students are willing to participate, administer the survey;

8. Ask the teacher to explain the consent form;

9. Allow any student to withdraw from the survey at any time without giving a reason;

10. Collect the survey papers, and thank all the participants;

11. Send the answer key to any instructor who requests it for interest or follow-up with the class;

12. Analyze the data, making sure the identity of participants is not divulged in any research reports. 
The General Ethics Review Board was very careful of the students' and teachers' rights, particularly their right to remain anonymous and their right to say no to participating in the research. In order to ensure that no participant felt even indirect coercion, the review board suggested that the researcher should contact the teachers directly rather than having the initial e-mail forwarded to them by their school director (and employer) and that the researcher should explain the survey to students rather than their teacher (the person responsible for their academic grade and someone whom they might not want to disappoint by opting out of a class activity).

Since the surveys we administered were completely anonymous, and the survey for students included the VSK shell, which made not knowing the vocabulary a legitimate response, we were not worried about disadvantaging or even demoralizing the student subjects.

\section{Letter Inviting Participation}

July 5, 2004

Dear student:

I am a visiting scholar (Canada-China Scholars' Exchange Program) at the Strathy Language Unit, English Department, Queen's University. I am doing research on English learners' acquisition of culture-specific vocabulary.

I would greatly appreciate it if you would participate in my survey regarding the learning of English words related to Canada.

Your participation in this study is, of course, completely voluntary. If you participate, you are advised not to put your name on the survey so that your anonymity and confidentiality will be protected. While filling out the survey, you can omit any question that you find objectionable. In fact, it is all right to decide in the middle of the survey not to finish it and/or not to submit it. Your answer to the survey is NOT part of your marks for the course.

Filling out the survey will probably take you about 20 minutes. There are no known risks to participating in this survey.

I will use the survey results to write a research article for an applied linguistic journal. Your personal identity, however, will never be disclosed in any kinds of analyses or reports.

If you have any questions, comments or complaints about the surveys, please contact me, XU Hai at [telephone, e-mail] or the Director of the School [name, telephone, e-mail] or the Chair of the General Research Ethics Board [name, telephone, e-mail].

Thank you for considering participating in my study.

Yours sincerely,

XU Hai

Visiting Scholar at the Strathy Language Unit, Queen's University

[e-mail] 